\title{
Effects of exposure to a cafeteria diet during gestation and after weaning on the metabolism and body weight of adult male offspring in rats
}

\author{
Amanda Brondani Mucellini ${ }^{1 *}$, Jéferson Ferraz Goularte ${ }^{1}$, Ana Carla de Araujo da Cunha ${ }^{1}$, \\ Rafael Corrêa Caceres ${ }^{1}$, Cristie Noschang ${ }^{2}$, Carla da Silva Benetti ${ }^{2}$, Patrícia Pelufo Silveira ${ }^{2}$ \\ and Gilberto Luiz Sanvitto ${ }^{1}$ \\ ${ }^{1}$ Department of Physiology, Institute of Basic Health Sciences, Federal University of Rio Grande do Sul, Rua Sarmento \\ Leite 500, Centro, Porto Alegre, Rio Grande do Sul, Brazil \\ ${ }^{2}$ Department of Paediatrics, Faculty of Medicine, Federal University of Rio Grande do Sul, Rua Ramiro Barcelos 2350, \\ Rio Branco, Porto Alegre, Rio Grande do Sul, Brazil
}

(Submitted 24 April 2013 - Final revision received 16 October 2013 - Accepted 18 October 2013 - First published online 13 December 2013)

\section{Abstract}

In the present study, we investigated whether maternal exposure to a cafeteria diet affects the metabolism and body composition of offspring and whether such an exposure has a cumulative effect during the lifetime of the offspring. Female rats were fed a control (CON) or a cafeteria (CAF) diet from their own weaning to the weaning of their offspring. At $21 \mathrm{~d}$ of age, male offspring were divided into four groups by diet during gestation and after weaning (CON-CON, CON-CAF, CAF-CON and CAF-CAF). Blood was collected from dams (after weaning) and pups (at 30 and $120 \mathrm{~d}$ of age) by decapitation. CAF dams had significantly greater body weight and adipose tissue weight and higher concentrations of total cholesterol, insulin and leptin than CON dams (Student's $t$ test). The energy intake of CAF rats was higher than that of CON rats regardless of the maternal diet (two-way ANOVA). Litters had similar body weights at weaning and at $30 \mathrm{~d}$ of age, but at $120 \mathrm{~d}$, CON-CAF rats were heavier. At both ages, CAF rats had greater adipose tissue weight than CON rats regardless of the maternal diet, and the concentrations of TAG and cholesterol were similar between the two groups, as were blood glucose concentrations at $30 \mathrm{~d}$ of age. However, at $120 \mathrm{~d}$ of age, CAF rats were hyperglycaemic, hyperinsulinaemic and hyperleptinaemic regardless of the maternal diet. These findings suggest that maternal obesity does not modulate the metabolism of male offspring independently, modifying body weight only when associated with the intake of a cafeteria diet by the offspring.

Key words: Maternal obesity: Body weight: Metabolic programming: Junk food: Developmental Origins of Health and Disease

Obesity has reached epidemic proportions, due in large part to the adoption of a lifestyle with increased energy intake and reduced physical activity ${ }^{(1,2)}$. The incidence of obesity during pregnancy has increased from 70 to $100 \%$ during the last decade, which is reflected by almost every maternal complication during pregnancy and increases the odds of short-term and long-term disturbances in fetal health, such as congenital abnormalities, inadequate size and weight, and risk of obesity and the metabolic syndrome ${ }^{(3-8)}$. This evidence points to the existence of an effect of maternal obesity across generations, suggesting that the maternal environment during the prenatal period appears to programme for the development of obesity and the metabolic syndrome in the offspring during childhood and adulthood ${ }^{(9-14)}$. Some studies have suggested that resistance to insulin and leptin observed in mothers may modulate fetal metabolic programming ${ }^{(15-19)}$; however, the mechanisms whereby maternal obesity affects offspring health are still unclear.

Another question that remains is whether maternal obesity alone can influence the genesis of obesity in offspring until adulthood or whether persistence of obesity into adulthood depends on the offspring following their obese mothers dietary patterns. Some studies have found evidence of intrauterine programming of obesity regardless of the offspring $\operatorname{diet}^{(5,20-22)}$. However, others have suggested that excessive weight and its consequent complications, such as the metabolic syndrome, occur only when the offspring of obese mothers are exposed to excessive dietary energy intake ${ }^{(23,24)}$

In addition to seeking evidence on the harm caused by maternal obesity to some parameters related to the metabolism of male offspring, the present study sought to investigate whether an interaction exists between obesity in mothers and

Abbreviations: CAF, cafeteria; CON, control; UFRGS, Federal University of Rio Grande do Sul.

*Corresponding author: A. B. Mucellini, fax +55 513308 3656, email amandabmuc@gmail.com 
obesity in their offspring. Hence, the aim of the present study was to test the hypotheses that induced maternal obesity has negative effects on offspring metabolism and that the offspring of obese mothers that are also subjected to the induction of obesity exhibit even greater negative effects on this outcome.

\section{Experimental methods}

The present study was carried out on Wistar rats obtained from the Centre for Laboratory Animal Reproduction and Experimentation of the Federal University of Rio Grande do Sul (UFRGS), Porto Alegre, Brazil. All the experiments were carried out in accordance with the Guide for the Care and Use of Laboratory Animals of the United States National Institutes of Health and were approved by the Animal Research Ethics Committee of UFRGS. The research project was approved with Committee judgement no. 21224 . Female rats ( $n$ 23) aged $21 \mathrm{~d}$ (average weight 45.79 (SEM 0.9581) g) were kept in vivaria under controlled temperature $\left(20-24^{\circ} \mathrm{C}\right)$ and luminosity ( $12 \mathrm{~h}$ light $-12 \mathrm{~h}$ dark cycle) conditions. The rats were randomly divided into two treatment groups: CON, receiving only standard chow (Nuvilab CR-1®) and water ad libitum from their own weaning to the weaning of their offspring, and $\mathrm{CAF}$, receiving standard chow, water and other items from a cafeteria diet (Table 1) ad libitum from their own weaning to the weaning of their offspring.

At $120 \mathrm{~d}$ of age, checking of the oestrous cycle by vaginal smears began. Material was collected with the aid of a dropper containing $70 \%$ saline. The vaginal epithelium of the female rats was rinsed with this solution, and the material thus collected was immediately analysed by optical microscopy to determine the current phase of the oestrous cycle. Female rats in the pro-oestrus phase that exhibited signs of sexual receptivity were mated with a control male rat. Female rats were considered possibly pregnant if spermatozoa were found in the vaginal canal the following morning. After birth and weaning, male offspring were divided into four groups depending on the maternal and offspring diets (Fig. 1): CON-CON ( $n$ 16), offspring of CON dams fed the control diet after weaning; CON-CAF ( $n$ 16), offspring of CON dams fed the cafeteria diet after weaning; CAF-CON ( $n$ 21), offspring of CAF dams fed the control diet after weaning; CAF-CAF ( $n$ 18), offspring of CAF dams fed the cafeteria diet after weaning. From day 16 of lactation to the day after weaning of their litter (day 22), CAF dams whose pups had been allocated to the CAF-CON group were fed the control diet so as to prevent the pups from consuming the cafeteria diet, as recommended by Tozuka et al. ${ }^{(25,26)}$. The dietary intake of the pups was recorded every $2 \mathrm{~d}$ from week 5 of treatment (age $49 \mathrm{~d}$ ) to the end of treatment (age $120 \mathrm{~d}$ ). Foods were provided in excess amounts, and intake was assessed by weighing the quantity provided and the quantity remaining of each item of the control and cafeteria diets individually. The daily data obtained for each food item were summed, generating total intake per $\mathrm{d}$, and total daily intakes were summed to obtain total weekly intake, which was then divided by the number of days of the week and the number of animals. The complete procedure has been described in detail in a previously published work ${ }^{(27)}$. Energy intake was evaluated on the basis of the nutritional composition of each item, and the results are expressed as weekly intake/animal per d. Dams and male offspring alike were weighed once a week; results are expressed as the weight on the day of weaning, weight on the day of death and weekly evolution of weight.

Dams were decapitated on the morning after weaning of their pups, at $210 \mathrm{~d}$ of age ( 30 weeks of treatment), and their male offspring were decapitated at one of two time points: at $30 \mathrm{~d}$ of age (9 d of treatment) or at $120 \mathrm{~d}$ (14 weeks of treatment) (Fig. 1). Decapitation was carried out using a rodent guillotine, after 12-14 h of fasting, between 08.30 and 12.00 hours. Blood was collected to obtain serum and plasma by centrifugation. The concentrations of total cholesterol, TAG and glucose in serum were quantified by a colorimetric method (Colesterol Liquiform, Triglicérides Liquiform, Glicose PAP Liquiform; Labtest $(\circledR)$, and the concentrations of insulin and leptin in plasma were quantified by ELISA, using commercial reagents (Rat/Mouse Insulin and Rat Leptin ELISA Kits; Millipore). Visceral adipose tissue was dissected by separating the adipose tissue around the stomach, spleen, pancreas, small and large intestines and reproductive tract and the retroperitoneal

Table 1. Nutritional composition of food items in the cafeteria diet

\begin{tabular}{|c|c|c|c|c|c|c|c|c|}
\hline & \multirow[b]{2}{*}{$\begin{array}{l}\text { Energy } \\
\text { (kJ/100 g) }\end{array}$} & \multicolumn{2}{|c|}{ Carbohydrates } & \multicolumn{2}{|c|}{ Protein } & \multicolumn{2}{|c|}{ Fat } & \multirow[b]{2}{*}{$\begin{array}{c}\mathrm{Na} \\
(\mathrm{mg} / 100 \mathrm{~g})\end{array}$} \\
\hline & & $\mathrm{g} / 100 \mathrm{~g}$ & $\begin{array}{l}\text { Percentage } \\
\text { of energy }\end{array}$ & $\mathrm{g} / 100 \mathrm{~g}$ & $\begin{array}{l}\text { Percentage } \\
\text { of energy }\end{array}$ & $\mathrm{g} / 100 \mathrm{~g}$ & $\begin{array}{l}\text { Percentage } \\
\text { of energy }\end{array}$ & \\
\hline Standard chow (Nuvilab CR-1 ${ }^{\circledR}$ ) & 1234 & 55 & 64 & 22 & 26 & 4 & 10,5 & 270 \\
\hline Salami (Majestade) & 1414 & 0 & 0 & 32 & 37 & 24 & 63 & 1248 \\
\hline Bread (Seven Boys) & 1234 & 53 & 75 & 9 & 13 & 4 & 13 & 470 \\
\hline Snack Yokitos (Yoki) & 2008 & 60 & 50 & 6 & 5 & 24 & 45 & 1104 \\
\hline Deliket Jelly Bean (Dori Alimentos) & 1590 & 95 & 100 & 0 & 0 & 0 & 0 & 20 \\
\hline Smoked sausage (Perdigão) & 1331 & 1 & $1 \cdot 1$ & 18 & 20 & 32 & 79 & 1573 \\
\hline Chocolate cake (Nutrella) & 1360 & 50 & 61 & 5 & 6 & 12 & 33 & 618 \\
\hline Biscuit Maizena (Isabela) & 1799 & 73 & 68 & 7 & 6 & 12 & 25 & 433 \\
\hline Marshmallow (Fini) & 1423 & 80 & 94 & 5 & 6 & 0 & 0 & 46 \\
\hline Ham (Sadia) & 649 & 0 & 0 & 17 & 46 & 9 & 54 & 833 \\
\hline Snack Fritello (Pavioli) & 2125 & 52 & 41 & 8 & 6 & 29 & 52 & 640 \\
\hline Chocolate wafer biscuits (Bauducco) & 2176 & 63 & 49 & 5 & 4 & 27 & 47 & 113 \\
\hline Gumdrop Gomets (Dori Alimentos) & 1506 & 90 & 100 & 0 & 0 & 0 & 0 & 50 \\
\hline Soft drink (Coca-Cola) & 178 & 11 & 100 & 0 & 0 & 0 & 0 & 5 \\
\hline
\end{tabular}




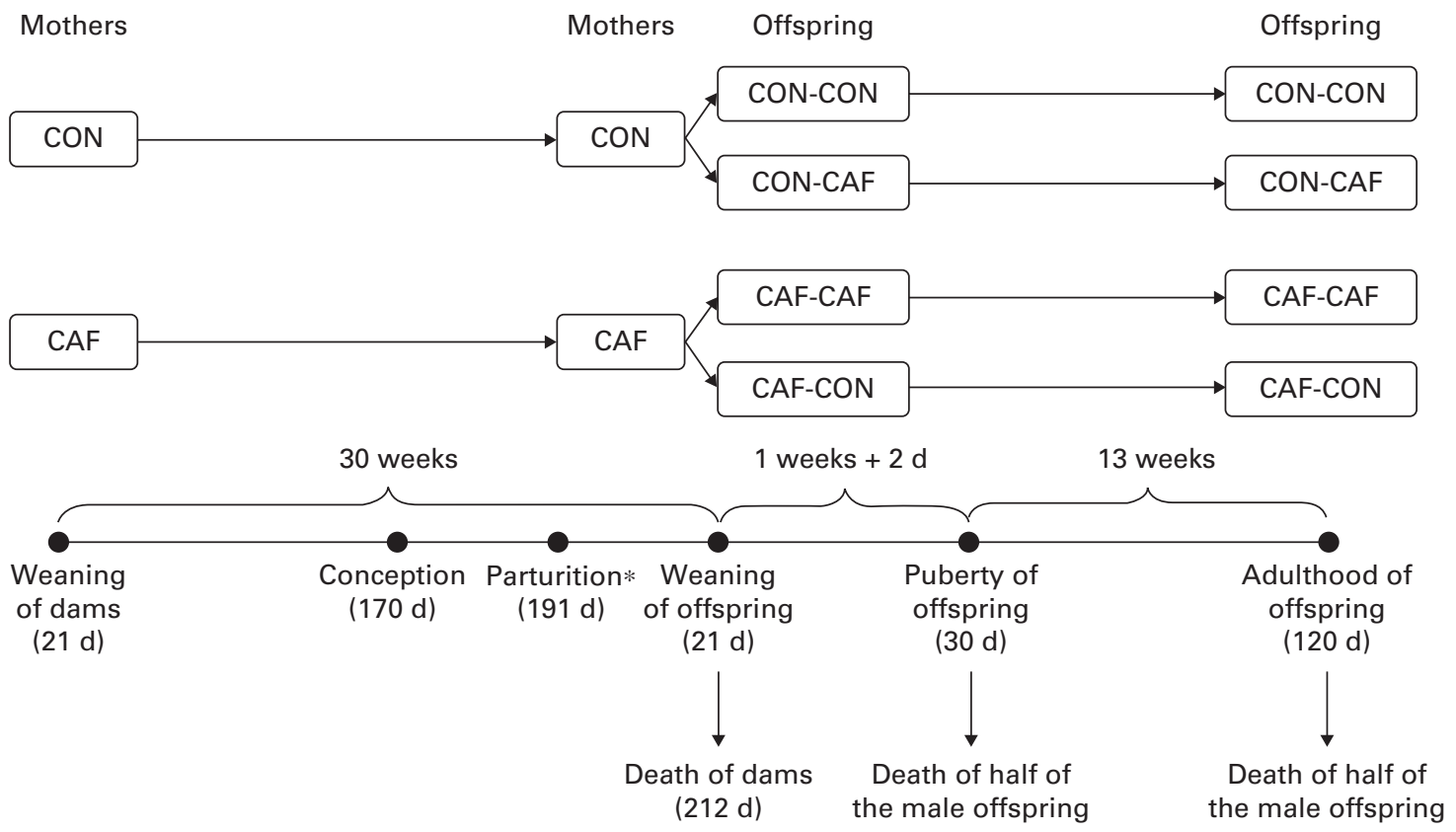

Fig. 1. Experimental design (see text for details). ${ }^{*}$ From day 16 of lactation to the day after weaning (day 22), CAF dams whose pups had been allocated to the CAF-CON group were fed the control diet. CON-CON, control offspring born to control mothers $(n 16)$; CON-CAF, cafeteria offspring born to control mothers $(n 16)$; CAF-CAF, cafeteria offspring born to cafeteria mothers ( $n$ 18); CAF-CON, control offspring born to cafeteria mothers $(n 21)$.

adipose tissue corresponding to the fat around and below the kidneys. Shortly after dissection, the fatty tissue samples were weighed and discarded.

\section{Statistical analyses}

The Kolmogorov-Smirnov test was used to assess the normality of data, and $F$ test was used to test the equality of variances. Student's $t$ test was used for between-group comparisons, and two-way ANOVA with Bonferroni post hoc correction was used to evaluate the effects of dam and pup exposures and the interactions between them. Multivariate analysis of repeated measures was used to evaluate the effect of dam and offspring exposures on the evolution of body weight and energy intake, as well as the interaction between treatments. Data are expressed as means with their standard errors. In all the cases, differences were considered significant when $P<0 \cdot 05$. Statistical analyses were carried out using GraphPad Prism ${ }^{\circledR}$
5.00 for Windows (GraphPad Software) and the Statistical Package for the Social Sciences (SPSS)® 19.0 for Windows (SPSS, Inc., IBM).

\section{Results}

Maternal body weight, adipose tissue weight, and total cholesterol, TAG, glucose, insulin and leptin concentrations at age $210 d$

At the end of the lactation period, CAF dams had significantly greater body weight and visceral and retroperitoneal adipose tissue weights than CON dams (Table 2). The total cholesterol concentrations of CAF dams were higher than those of CON dams at the same time point. The concentrations of TAG and glucose were similar between the groups. However, CAF dams had significantly higher concentrations of insulin and leptin than CON dams.

Table 2. Maternal metabolic characteristics at the end of treatment ( $210 \mathrm{~d}$ of age)

(Number of rats and mean values with their standard errors)

\begin{tabular}{|c|c|c|c|c|c|c|c|}
\hline & \multicolumn{3}{|c|}{ CON } & \multicolumn{3}{|c|}{ CAF } & \multirow[b]{2}{*}{$P$} \\
\hline & $n$ & Mean & SEM & $n$ & Mean & SEM & \\
\hline Body weight (g) & 14 & 275.4 & 4.426 & 9 & $305 \cdot 0^{* *}$ & 10.76 & 0.008 \\
\hline Visceral adipose tissue weight/body weight (\%) & 14 & 1.713 & 0.174 & 7 & $4 \cdot 347^{\star *}$ & 1.030 & 0.002 \\
\hline Retroperitoneal adipose tissue weight/body weight (\%) & 14 & 0.430 & 0.048 & 7 & $1.193^{\star \star}$ & 0.336 & 0.005 \\
\hline Total cholesterol $(\mathrm{mmol} / \mathrm{l})$ & 9 & 2.460 & $0 \cdot 160$ & 7 & $3.765^{\star}$ & 0.488 & 0.014 \\
\hline $\mathrm{TAG}(\mathrm{mmol} / \mathrm{l})$ & 9 & $1 \cdot 135$ & 0.167 & 7 & 1.560 & 0.236 & 0.152 \\
\hline Glucose $(\mathrm{mmol} / \mathrm{l})$ & 9 & 6.094 & 0.207 & 7 & 6.772 & 0.311 & 0.080 \\
\hline Insulin (pmol/l) & 8 & $118 \cdot 7$ & 13.59 & 6 & $220 \cdot 6^{*}$ & 41.82 & 0.023 \\
\hline Leptin $(\mathrm{pmol} / \mathrm{l})$ & 8 & $117 \cdot 1$ & 22.87 & 6 & $233.9^{\star}$ & $37 \cdot 12$ & 0.015 \\
\hline
\end{tabular}

CON, control mothers; CAF, cafeteria mothers.

Mean value was significantly different from that of the control group: ${ }^{\star} P<0.05,{ }^{\star \star} P<0.01$. 
Effect of maternal and offspring diets on the body weight, adipose tissue weight, and total cholesterol, TAG and glucose concentrations of male offspring at age $30 \mathrm{~d}$

On the day of weaning, at $21 \mathrm{~d}$ of age, corresponding to the first day of exposure to the different diets, the male offspring of CON and CAF dams had similar body weights $(P=0.857)$ (data not shown). At $30 \mathrm{~d}$ of age, body weights were still similar among the offspring groups (Table 3), with no effect of maternal exposure and no interaction between the maternal and offspring diets, although there was a trend towards an effect of the offspring diet. At the same time point, CAF offspring had greater retroperitoneal and visceral adipose tissue weights than CON offspring, regardless of the maternal diet, and there was no interaction between the maternal and offspring diets. At $30 \mathrm{~d}$ of age, the concentrations of total cholesterol, TAG and glucose were also similar across all the offspring groups (Table 4), with no effect of offspring or maternal diet and no interaction between the offspring and maternal exposures. The evolution of body weight over time was influenced by the maternal diet, and there was a trend towards an interaction between the maternal and offspring diets, but there was no effect of the offspring diet (Fig. 2). The evolution of the energy intake of offspring over time was influenced by the offspring diet; there was no effect of maternal diet and no interaction between the maternal and offspring diets (Fig. 3)

Effect of maternal and offspring diets on the body weight, adipose tissue weight, and total cholesterol, TAG and glucose concentrations of male offspring at age $120 \mathrm{~d}$

At $120 \mathrm{~d}$ of age, the body weight of offspring was affected by the offspring diet (Table 3), by the maternal diet, and by the interaction between the offspring and maternal exposures. At the same time point, visceral and retroperitoneal adipose tissue weights were influenced by the offspring diet alone, with no effect of maternal diet and no interaction between the offspring and maternal exposures. At $120 \mathrm{~d}$ of age, the concentrations of total cholesterol and TAG were also similar across all the offspring groups (Table 4), with no effect of offspring or maternal diet and no interaction between the offspring and maternal exposures. The concentrations of glucose were also influenced by the offspring diet, with no effect of maternal diet and no interaction between the offspring and maternal exposures. Similarly, at $120 \mathrm{~d}$ of age, the concentrations of insulin and leptin of offspring were affected by the offspring diet, with no effect of maternal diet and no interaction between the offspring and maternal exposures.

\section{Discussion}

The findings of the present study suggest that maternal diet does not affect the metabolism of male offspring that are exposed to a control diet during their lifetime. Furthermore, when both mother and offspring ingested the cafeteria diet, they exhibited metabolic effects the same as those exhibited by the offspring of control dams that were fed the cafeteria

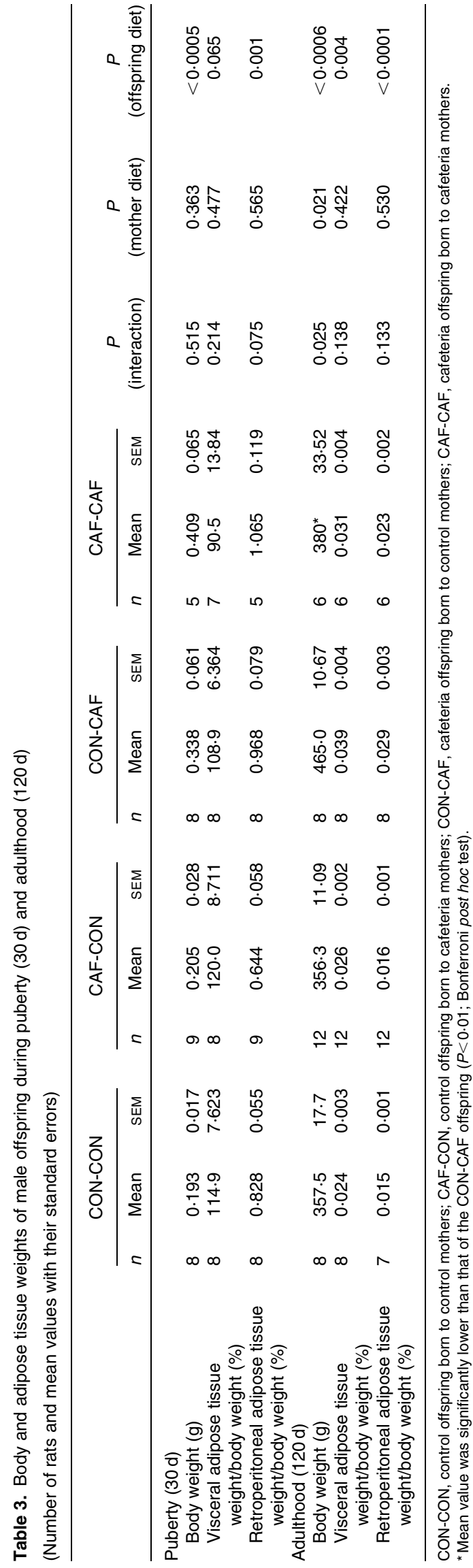


diet after weaning. However, when both mother and offspring were ingested the cafeteria diet, the offspring exhibited a different pattern of change in body weight compared with the offspring that were fed the cafeteria diet after weaning and were born to control dams, suggesting that the maternal environment during gestation and lactation affects the body composition of offspring in adulthood.

Dams that ingested the cafeteria diet developed a body habitus and a metabolic profile characteristic of obesity, as indicated by significant increases in body weight, visceral and retroperitoneal adipose tissue weights, and concentrations of total cholesterol, insulin and leptin. However, circulating concentrations of glucose and TAG remained the same in the two treatment groups. Even if insulin and leptin were dosed in the post-gestational period, exactly on the day after weaning of offspring, it is believed that the concentrations of these hormones would already have been high during pregnancy, as gestation is a condition in which physiological metabolic changes that promote resistance to these hormones occur $^{(28-30)}$. Furthermore, studies in obese females fed hyperenergetic diets found hyperinsulinaemia and hyperleptinaemia during pregnancy ${ }^{(31,32)}$. This evidence suggests that CAF dams were possibly (at the very least) hyperinsulinaemic and hyperleptinaemic while pregnant and, therefore, that their offspring were probably exposed to a metabolically altered environment during the fetal period.

The total energy intake of offspring that were fed the control diet and were descendants of dams that were fed the cafeteria diet was similar to that of pups that were fed the control diet and descendants of control dams. Many studies have attempted to investigate the influence of hyperenergetic maternal feeding on feeding behaviour of offspring, with contradictory results. Some have found no differences in energy intake ${ }^{(20,23,33,34)}$, as has been observed in the present study, while others have reported higher energy intake among offspring fed a control diet but born to mothers exposed to hyperenergetic diets ${ }^{(31,32)}$. The above-cited studies have major methodological differences, thus precluding any strict comparisons between them. As expected, the energy intake of pups that were fed the cafeteria diet and born to control dams was higher than that of control pups born to control dams, a difference attributable to the fact that the cafeteria diet consists of hyperenergetic items and that intake of chow is progressively replaced by these items ${ }^{(20,27,35,36)}$. Pups that were fed the cafeteria diet from the fetal period to adulthood exhibited an energy intake greater than that of control pups, but similar to that of pups that were fed the cafeteria diet only after weaning. This is consistent with the findings of previous studies ${ }^{(23,34,37)}$.

Treatment exposures were initiated in all the pups at $21 \mathrm{~d}$ of age with similar body weights, which shows that ingestion of the cafeteria diet by dams before pregnancy and during gestation and lactation did not affect total body weight; this is consistent with the findings of previous research ${ }^{(21,23,32,33)}$. The body weights and visceral and retroperitoneal adipose tissue weights of pups fed the cafeteria diet during the prenatal and lactation periods were similar to those of control pups born to control dams at puberty, which is consistent with the findings of some prior studies ${ }^{(23,33)}$. While pubertal 


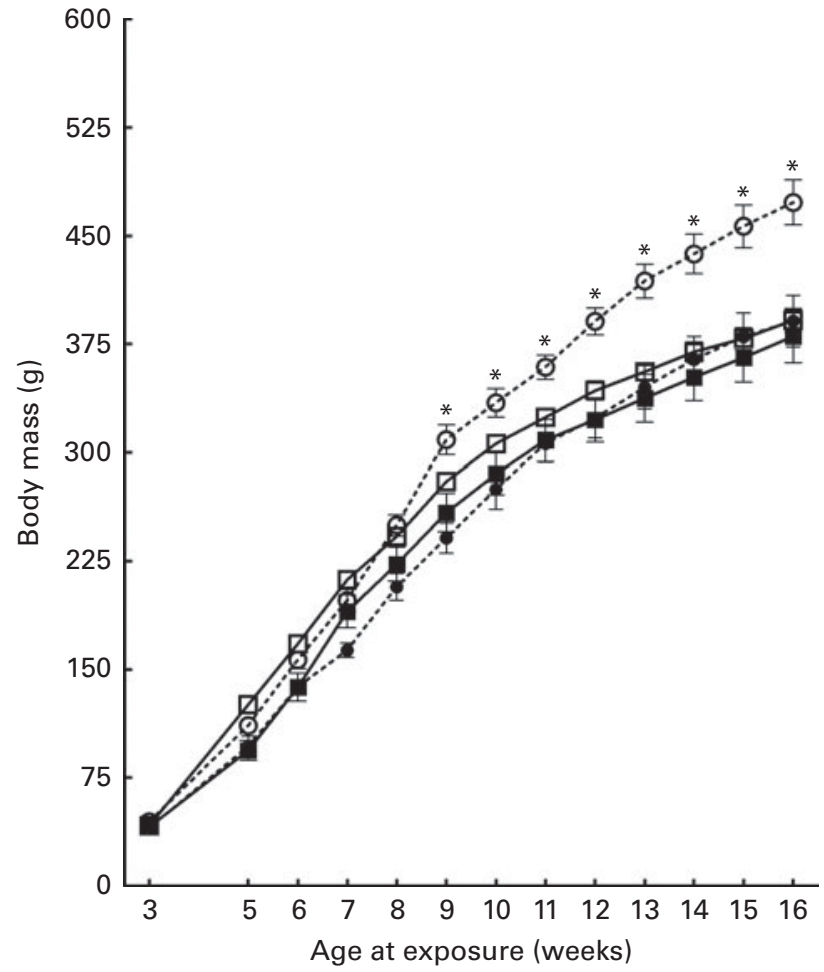

Fig. 2. Evolution of the body weight of pups over the 14-week experimental period. Values are means, with their standard errors represented by vertical bars. Treatment was initiated at $21 \mathrm{~d}$ of age in male offspring. However, intake data were recorded only from week 5 of treatment (age 7 weeks) to the end of treatment at week 14 (age 16 weeks). CON-CON ( $\square$ ), control offspring born to control mothers $(n 16)$; CON-CAF (-.--), cafeteria offspring born to control mothers ( $n$ 16); CAF-CON (- -), control offspring born to cafeteria mothers $(n 21)$; CAF-CAF $(.-$.$) , cafeteria offspring born to cafeteria$ mothers $(n 18)$. The evolution of body weight over time was influenced by the maternal diet, and there was a trend towards an interaction between the maternal and offspring diets (for further details, see text). * Mean value was significantly different for the CON-CAF group from that of the other groups from week $10(P<0.05$; Bonferroni post hoc test).

body weight of pups fed the cafeteria diet after weaning was similar to that of control pups born to control dams, retroperitoneal and visceral adipose tissue weights of these pups were already significantly higher, suggesting that, at least during puberty, body composition is different despite similar total body weights ${ }^{(21,38)}$. Furthermore, this demonstrates that periods as short as $9 \mathrm{~d}$ of exposure to a cafeteria diet (from weaning to puberty) can affect fat accretion. In addition, despite the fact that pups fed the cafeteria diet from the prenatal period to adulthood had pubertal body weight comparable to that of the other groups, these pups had visceral and retroperitoneal adipose tissue weights greater than those of pups fed the control diet, regardless of the maternal diet. Again, this indicates that the body composition of pups fed the cafeteria diet was different from that of pups fed the control diet, even though all the four groups had similar total body weights.

The pubertal concentrations of total cholesterol, TAG and glucose of pups fed the cafeteria diet only during the fetal and lactation periods were similar to those of control pups born to control dams. To date, similar results have been reported only by a few studies ${ }^{(23,31,32)}$. However, these findings indicate that even in pups born to obese mothers, ingestion of the control diet prevents the expression of a metabolic phenotype characteristic of obesity. Similar results were observed during puberty in pups that began eating the cafeteria diet immediately after weaning, as there were no changes in circulating cholesterol, TAG or glucose concentrations; similarly, pups born to obese dams and fed the cafeteria diet had circulating glucose, TAG and total cholesterol concentrations similar to those of the other groups.

Pups that were born to control dams and fed the cafeteria diet after weaning (CON-CAF) had higher total body weight and visceral and retroperitoneal adipose tissue weights in adulthood when compared with pups born to control dams and fed the control diet (CON-CON), showing that the cafeteria diet had an obesogenic effect in these pups ${ }^{(35,39)}$. On the other hand, pups born to obese dams and fed the cafeteria diet (CAF-CAF) had a total body weight similar to that of control pups born to control dams and lower than that of pups fed the cafeteria diet from weaning.

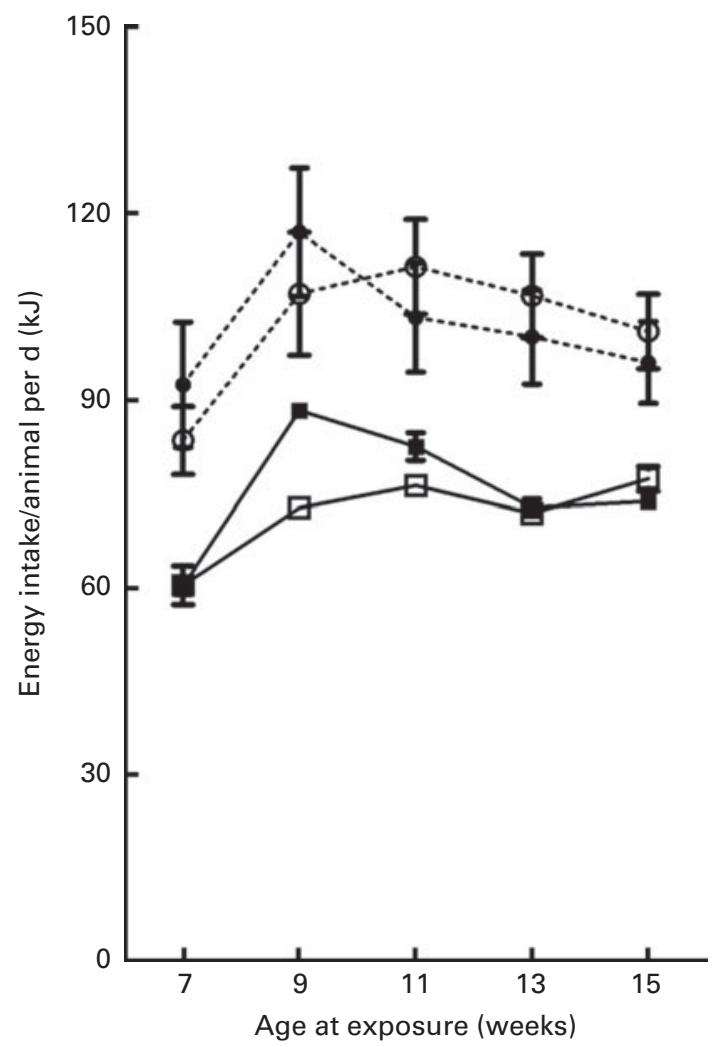

Fig. 3. Evolution of energy intake/animal per d over the 14-week experimental period. Values are means, with their standard errors represented by vertical bars. Treatment was initiated at $21 \mathrm{~d}$ of age in male offspring. However, intake data were recorded only from week 5 of treatment (age 7 weeks) to the end of treatment at week 14 (age 16 weeks). CON-CON (־), control offspring born to control mothers $(n 16)$; CON-CAF $(-\odot \cdot)$, cafeteria offspring born to control mothers ( $n$ 16); CAF-CON (- $)$, control offspring born to cafeteria mothers ( $n 21)$; CAF-CAF (-- ), cafeteria offspring born to cafeteria mothers ( $n$ 18). According to multivariate repeated-measures ANOVA, energy intake was influenced by the offspring diet (for further details, see text). 
These data can be explained in several ways. For instance, an increase in maternal leptin levels (especially in milk) would prevent increases in energy intake (and consequently body weight) in offspring continuously exposed to the cafeteria $\operatorname{diet}^{(40,41)}$ when compared with pups born to control dams and first exposed to the cafeteria diet after weaning. These body weight findings run counter to the results of many studies that have found that maternal diet energy increases offspring susceptibility to obesity ${ }^{(20,32,34)}$, but are consistent with the findings of recent studies ${ }^{(5,37)}$ describing that offspring born to mothers exposed to a high-energy diet are protected from obesity induction. Exposure to a hyperenergetic diet in utero may have led to adaptations conferring a greater ability to deal with an equally energy-rich environment after birth, thus serving as a form of predictive adaptive response to this exposure to high levels of lipids and carbohydrates during the fetal and postnatal periods ${ }^{(42,43)}$, possibly through epigenetic modification in the central control of intake ${ }^{(44,45)}$.

Despite this, in adulthood, the retroperitoneal and visceral adipose tissue weights of CAF-CAF pups were greater than those of CON-CON pups and similar to those of CON-CAF pups. Considering that the total body weight of CAF-CAF pups was lower than that of CON-CAF pups, but that these two groups had similar visceral and retroperitoneal adipose tissue weights, one could propose that maternal obesity exerts an effect on body structure, possibly by increasing fat mass relative to lean mass and by further reducing lean mass ${ }^{(21,37)}$. This theory is consistent with studies that showed that obese mothers have higher chances of having children with low birth weight ${ }^{(46)}$, but that these offspring have greater adiposity, altered muscle development and increased risk for the metabolic syndrome ${ }^{(47)}$ with the passing of years, possibly also through epigenetic modulation ${ }^{(48,49)}$. However, further research into the musculoskeletal composition of all the treatment groups is required to confirm this hypothesis.

The concentrations of TAG and cholesterol remained the same across all the four groups in adulthood. However, in adulthood, blood glucose, insulin and leptin concentrations of pups that were fed the cafeteria diet were elevated compared with those of pups that were fed the control diet, regardless of the maternal diet, thus confirming the finding of leptin and insulin resistance and glucose intolerance in animals exposed to a cafeteria diet ${ }^{(50,51)}$. These findings refute the hypothesis of an influence of maternal obesity and its interaction with offspring diet in the metabolic state, but instead provide evidence of a greater influence of the food choices of each generation on the biochemical parameters of the individuals of that generation.

Given the conditions under which the present study was carried out, it can be concluded that the cafeteria diet induced obesity in dams and that this condition did not affect the metabolic parameters of their male offspring at 30 and $120 \mathrm{~d}$ of age, but it did modify body weight in adulthood among offspring also exposed to the cafeteria diet. Nevertheless, further studies on body composition are needed to elucidate these results. The present study emphasises the importance of food preferences throughout life and suggests that choices can reverse the effects of a metabolically altered maternal environment and its programming. Furthermore, it suggests that both maternal and offspring dietary intakes must be appropriate to ensure optimal body composition in the next generations.

\section{Acknowledgements}

The authors appreciate the collaboration of Grace Violeta Espinoza Pardo during the experimental procedures.

The present study was supported by the National Council for Technological and Scientific Development (CNPq), the Coordination for Improvement of Higher Education Personnel (Capes) and the Graduate Studies Division at UFRGS (PROPG). The financial backers played no role in the design and analysis of the study or in the writing of this article.

The authors' contributions are as follows: A. B. M. was involved in all stages of the study design, experimental procedures, data analysis and manuscript writing; J. F. G., C. N. and C. S. B. contributed to the experimental procedures, data analysis and manuscript writing; A. C. A. C. and R. C. C. were involved in all stages of the experimental procedures; P. P. S. and G. L. S. contributed to the study design, data analysis and manuscript writing.

The authors have no conflicts of interest to declare.

\section{References}

1. World Health Organization (2013) Obesity and Overweight Geneva: World Health Organization. http://www.who.int/ mediacentre/factsheets/fs311/en/index.html

2. Block G, Rosenberger WF \& Patterson BH (1988) Calories, fat and cholesterol: intake patterns in the US population by race, sex and age. Am J Public Health 78, 1150-1155.

3. Guelinckx I, Devlieger R, Beckers K, et al. (2008) Maternal obesity: pregnancy complications, gestational weight gain and nutrition. Obes Rev 9, 140-150.

4. Huda SS, Brodie LE \& Sattar N (2010) Obesity in pregnancy: prevalence and metabolic consequences. Semin Fetal Neonatal Med 15, 70-76.

5. Howie GJ, Sloboda DM, Kamal T, et al. (2009) Maternal nutritional history predicts obesity in adult offspring independent of postnatal diet. J Physiol 587, 905-915.

6. Crozier SR, Inskip HM, Godfrey KM, et al. (2010) Weight gain in pregnancy and childhood body composition: findings from the Southampton Women's Survey. Am J Clin Nutr 91, 1745-1751.

7. Melzer K \& Schutz Y (2010) Pre-pregnancy and pregnancy predictors of obesity. Int J Obes (Lond) 34, Suppl. 2, S44-S52.

8. Heerwagen MJ, Miller MR, Barbour LA, et al. (2010) Maternal obesity and fetal metabolic programming: a fertile epigenetic soil. Am J Physiol Regul Integr Comp Physiol 299, 711-722.

9. Desai M, Beall M \& Ross MG (2013) Developmental origins of obesity: programmed adipogenesis. Curr Diab Rep $\mathbf{1 3}$ $27-33$.

10. Symonds ME, Mendez MA, Meltzer HM, et al. (2013) Early life nutritional programming of obesity: mother-child cohort studies. Ann Nutr Metab 62, 137-145.

11. Wang X-M (2013) Early life programming and metabolic syndrome. World J Pediatr 8, 5-8.

12. Barker DJP (2007) Obesity and early life. Obes Rev 8, 45-49.

13. Hanley B, Dijane J, Fewtrell M, et al. (2010) Metabolic imprinting, programming and epigenetics - a review of 
present priorities and future opportunities. Br J Nutr $\mathbf{1 0 4}$ S1-S25.

14. Stocker CJ, Arch JRS \& Cawthorne MA (2007) Fetal origins of insulin resistance and obesity. Proc Nutr Soc 64, 143-151.

15. McMillen IC, Muhlhausler BS, Duffield JA, et al. (2004) Prenatal programming of postnatal obesity: fetal nutrition and the regulation of leptin synthesis and secretion before birth. Proc Nutr Soc 63, 405-412.

16. Ahlsson F, Diderholm B, Ewald U, et al. (2013) Adipokines and their relation to maternal energy substrate production, insulin resistance and fetal size. Eur $J$ Obstet Gynecol Reprod Biol 168, 26-29.

17. Tessier DR, Ferraro ZM \& Gruslin A (2013) Role of leptin in pregnancy: consequences of maternal obesity. Placenta $\mathbf{3 4}$, 205-211.

18. Catalano PM (2010) Obesity, insulin resistance, and pregnancy outcome. Reproduction 140, 365-371.

19. Catalano PM, Kirwan JP, Haugel-de Mouzon S, et al. (2003) Gestational diabetes and insulin resistance: role in shortand long-term implications for mother and fetus. $J$ Nutr 133, 1674S-1683S.

20. Bayol SA, Farrington SJ \& Stickland NC (2007) A maternal 'junk food' diet in pregnancy and lactation promotes an exacerbated taste for 'junk food' and a greater propensity for obesity in rat offspring. BrJ Nutr 98, 843-851.

21. Bayol SA, Simbi BH \& Stickland NC (2005) A maternal cafeteria diet during gestation and lactation promotes adiposity and impairs skeletal muscle development and metabolism in rat offspring at weaning. $J$ Physiol 567, 951-961.

22. White CL, Purpera MN \& Morrison CD (2009) Maternal obesity is necessary for programming effect of high-fat diet on offspring. Am J Physiol Integr Com Physiol 296, 1464-1472.

23. Akyol A, McMullen S \& Langley-Evans SC (2011) Glucose intolerance associated with early-life exposure to maternal cafeteria feeding is dependent upon post-weaning diet. Br J Nutr 107, 964-978.

24. Tamashiro KLK, Terrillion CE, Hyun J, et al. (2009) Prenatal stress or high-fat diet increases susceptibility to diet-induced obesity in rat offspring. Blood 58, 1116-1125.

25. Tozuka Y, Kumon M, Wada E, et al. (2010) Maternal obesity impairs hippocampal BDNF production and spatial learning performance in young mouse offspring. Neurochem Int $\mathbf{5 7}$ $235-247$.

26. Tozuka Y, Wada E \& Wada K (2009) Diet-induced obesity in female mice leads to peroxidized lipid accumulations and impairment of hippocampal neurogenesis during the early life of their offspring. FASEB J 23, 1920-1934.

27. Goularte JF, Ferreira MBC \& Sanvitto GL (2012) Effects of food pattern change and physical exercise on cafeteria diet-induced obesity in female rats. Br J Nutr 108, 1511-1518.

28. Trujillo ML, Spuch C, Carro E, et al. (2011) Hyperphagia and central mechanisms for leptin resistance during pregnancy. Endocrinology 152, 1355-1365.

29. Dahlgren J (2006) Pregnancy and insulin resistance. Metab Syndr Relat Disord 4, 149-152.

30. Grattan DR, Ladyman SR \& Augustine RA (2007) Hormonal induction of leptin resistance during pregnancy. Physiol Behav 91, 366-374.

31. Nivoit P, Morens C, Assche FAV, et al. (2009) Established diet-induced obesity in female rats leads to offspring hyperphagia, adiposity and insulin resistance. Diabetologia $\mathbf{5 2}$, 1133-1142.

32. Samuelsson A-M, Matthews PA, Argenton M, et al. (2008) Hypertension, and insulin resistance: a novel murine model of developmental. Hypertension 2007, 383-392.
33. Wright TM, Fone KCF, Langley-Evans SC, et al. (2011) Exposure to maternal consumption of cafeteria diet during the lactation period programmes feeding behaviour in the rat. Int J Dev Neurosci 29, 785-793.

34. Shankar K, Harrell A, Liu X, et al. (2008) Maternal obesity at conception programs obesity in the offspring. Am J Physiol Regul Integr Comp Physiol 294, 528-538.

35. Shafat A, Murray B \& Rumsey D (2009) Energy density in cafeteria diet induced hyperphagia in the rat. Appetite $\mathbf{5 2}$, $34-38$.

36. Prats E, Monfar M, Castell J, et al. (1989) Energy intake of rats fed a cafeteria diet. Physiol Behav 45, 263-272.

37. Ong ZY \& Muhlhausler BS (2011) Maternal "junk-food" feeding of rat dams alters food choices and development of the mesolimbic reward pathway in the offspring. FASEB J $\mathbf{2 5}$, 2167-2179.

38. Benkalfat NB, Merzouk H, Bouanane S, et al. (2011) Altered adipose tissue metabolism in offspring of dietary obese rat dams. Clin Sci (Lond) 121, 19-28.

39. Rothwell NJ \& Stock MJ (1979) Regulation of energy balance in two models of reversible obesity in the rat. J Comp Physiol Psychol 93, 1024-1034.

40. Picó C, Oliver P \& Sanchéz J (2007) The intake of physiology doses of leptin during lactation in rats prevents obesity in later life. Int J Obes 31, 1199-1209.

41. Sanchéz J, Priego T \& Paulou M (2008) Oral supplementation with physiological doses of leptin during lactation in rats improves insulin sensitivity and affects food preferences. Endocrinology 149, 733-740.

42. Gluckman PD \& Hanson MA (2004) Living with the past: evolution, development, and patterns of disease. Science 305, 1733-1736.

43. Gluckman PD \& Hanson MA (2004) Maternal constraint of fetal growth and its consequences. Semin Fetal Neonatal Med 9, 419-425.

44. Garratt E, Vickers M, Gluckman P, et al. (2013) Tissuespecific 5' heterogeneity of PPAR $\alpha$ transcripts and their differential regulation by leptin. PLOS ONE 8, e67483.

45. Plagemann A, Harder T, Brunn M, et al. (2009) Hypothalamic proopiomelanocortin promoter methylation becomes altered by early overfeeding: an epigenetic model of obesity and the metabolic syndrome. J Physiol 589, 4963-4976.

46. McDonald SD, Han Z, Mulla S, et al. (2010) Overweight and obesity in mothers and risk of preterm birth and low birth weight infants: systematic review and meta-analyses. BMJ 341, c3428.

47. Drake AJ \& Reynolds RM (2010) Impact of maternal obesity on offspring obesity and cardiometabolic disease risk. Reproduction 140, 387-398.

48. Yan X, Zhu MJ, Xu W, et al. (2010) Up-regulation of Toll-like receptor 4/nuclear factor- $\mathrm{\kappa B}$ signaling is associated with enhanced adipogenesis and insulin resistance in fetal skeletal muscle of obese sheep at late gestation. Endocrinology 151, 380-387.

49. Tong J, Yan X, Zhu M, et al. (2009) Maternal obesity downregulates myogenesis and $\beta$-catenin signaling in fetal skeletal muscle. Am J Physiol Endocrinol Metab 296, 917-924.

50. Sampey BP, Vanhoose AM, Winfield HM, et al. (2011) Cafeteria diet is a robust model of human metabolic syndrome with liver and adipose inflammation - comparison to highfat diet. Obesity 19, 1109-1117.

51. Castell-Auví A, Cedó L, Pallarès V, et al. (2012) The effects of a cafeteria diet on insulin production and clearance in rats. Br J Nutr 108, 1155-1162. 